\title{
Competing Concepts of Inequality in the Globalization Debate
}

\author{
Martin Ravallion* \\ World Bank \\ 1818 H Street NW, Washington DC, 20433, USA
}

\begin{abstract}
Differences in the value judgments made in measuring inequality underlie the conflicting factual claims often heard about how much poor people have shared in the economic gains from globalization. Opponents in the debate differ in: (i) whether they weight people or countries equally in assessing the extent of inequality; (ii) the weight they give to vertical inequalities versus horizontal inequalities and (iii) the extent to which they care about relative inequality versus absolute inequality. The value judgments on these issues made by both sides need greater scrutiny if the globalization debate is to move forward.
\end{abstract}

Keywords: Globalization, inequality, poverty, value judgments

JEL: D63, F02, O15

World Bank Policy Research Working Paper 3243, March 2004

The Policy Research Working Paper Series disseminates the findings of work in progress to encourage the exchange of ideas about development issues. An objective of the series is to get the findings out quickly, even if the presentations are less than fully polished. The papers carry the names of the authors and should be cited accordingly. The findings, interpretations, and conclusions expressed in this paper are entirely those of the authors. They do not necessarily represent the view of the World Bank, its Executive Directors, or the countries they represent. Policy Research Working Papers are available online at http://econ.worldbank.org.

* Martin Ravallion is with the World Bank's Research Group. For comments the author is grateful to Abhijit Banerjee, Jean-Yves Duclos, Francisco Ferreira, Emanuela Galasso, Ravi Kanbur, Peter Lambert, Branko Milanovic, Berk Ozler, Lant Pritchett, Eric Thorbecke, Dominique van de Walle, Adam Wagstaff and participants at the workshop for the Brookings Trade Forum, 2004. Email address:

mravallion@worldbank.org . 


\section{Introduction}

How much are the world's poor sharing in the gains from the economic growth fueled by greater economic integration? There are seemingly conflicting answers from the two sides of the ongoing debate on globalization and inequality. On one side, the website of a prominent NGO in the anti-globalization movement, the International Forum on Globalization, confidently claims that "globalization policies have ... increased inequality between and within nations." stands in marked contrast to the claims made by those more favorable to globalization; for example, an article in The Economist magazine states with equal confidence that: "Globalization raises incomes, and the poor participate fully" (The Economist, May 27, 2000, p.94).

Why do such different views persist? Surely the evidence would be conclusive one way or the other? I have heard it claimed by a prominent advocate for one side of this debate that the other side is simply "ignorant of the facts." But surely the facts would be clear enough by now?

It must be acknowledged that the available data on poverty and inequality are far from ideal, though neither side of this debate has paid much attention to the data problems. ${ }^{2}$ There are also potentially important differences in the types of data used. The "pro-globalization" side has tended to prefer "hard" quantitative data while the other side has drawn more eclectically on various types of evidence, both systematic and anecdotal or subjective. Differences in the data used no doubt account in part for the differing positions taken. However, since both sides have had access to essentially the same data, it does not seem plausible that such large and persistent differences in the claims made about what is happening to inequality in the world stem entirely from one side's "ignorance of the facts."

\footnotetext{
1 See http://www.ifg.org/store.htm. Similarly, the Policy Director of Oxfam writes that: "There is plenty of evidence that current patterns of growth and globalization are widening income disparities" (Letter to The Economist, June 20, 2000, p.6).

2 For a fuller discussion of the data and measurement issues underlying the globalization debate see Ravallion (2003).
} 
One reason why such different views persist is that it is difficult to separate out the effects of globalization from the many other factors impinging on how the distribution of income is evolving in the world. The processes of global economic integration are so pervasive that it is hard to say what the world would be like without them. ${ }^{3}$ These difficulties of attribution provide ample fuel for debate, though they also leave one suspicious of the confident claims made by both sides.

Conflicting assessments can also stem from hidden contextual factors. Diverse impacts of the same growth-promoting policies on inequality can be expected given the differences between countries in initial conditions. Policy reforms shift the distribution of income in different directions in different countries. Yet both sides make generalizations about distributional impacts without specifying the context. In a given country setting, there may well be much less to disagree about.

This paper looks into another possible reason for the continuing debate about the facts: the two sides in this debate do not share the same values about what constitutes a just distribution of the gains from globalization. The empirical facts in contention do not stem solely from objective data on incomes, prices and so on, but also depend on value judgments made in measurement — judgments that one may or may not accept. It can hardly be surprising that different people hold different normative views about inequality. And it is well understood in economics that those views carry weight for how one defines and measures inequality, though recognizing that it is ethics not economics that determines what trade-offs one accepts between the welfare of different people. An important class of "ethical measures" of inequality are built

\footnotetext{
3 Basu (2003, p.898) put is nicely: "In reality, globalization is a bit like gravity. We may discuss
} endlessly whether it is good or bad but the question of not having it does not seriously arise." 
on this realization. ${ }^{4}$ What is more notable in the present context is that important differences in values have become embedded in the methodological details underlying statements about what is happening to inequality in the world. ${ }^{5}$ The differences are rarely brought to the surface and argued out properly in this debate. ${ }^{6}$

The paper points to three differences in the value judgments made about distributive justice underlying the globalization debate. The first concerns one of the favorite empirical claims of the critics of globalization, namely that inequality between countries has been rising in the period of globalization — suggesting that the gains have been unfairly distributed. The proglobalization side disputes this, arguing instead that inequality between countries has been falling over the last 20 years or so. The value judgment here relates to whether one should weight countries equally or people equally when assessing distributional outcomes.

The second difference in concepts of inequality relates to how much weight one should attach to the way average gains from reform vary with income, versus the differences in impacts found at a given level of income. The pro-globalization side has tended to focus on aggregate measures of inequality or poverty, while the anti-globalization side has pointed to the losers amongst the poor and those vulnerable to poverty, thought often to the point of ignoring the aggregate outcomes. A value judgment underlying this difference in perspective relates to the weight one attaches to horizontal versus vertical inequality when assessing distributional impacts of globalization.

\footnotetext{
$4 \quad$ A seminal early contribution was made by Atkinson (1970). For an excellent survey of approaches to the measurement of inequality see Cowell (2000).

This is not an isolated instance of the blurring of facts and values; for further discussion see Putnam (2002).

$6 \quad$ More generally, economists have been reticent to debate values, preferring to focus on "facts." This has led some observers to argue that modern economics has become divorced from ethics, though that is a questionable characterization, as Dasgupta (2003) argues forcefully.
} 
The third issue concerns another distinction between two concepts of inequality; one is relative inequality, which depends solely on proportionate differences in incomes, while the other is absolute inequality, which depends on the absolute differences — the "income gap between rich and poor." Virtually all the research by economists on world inequality has used the former concept, which has then become embedded in more popular writings supporting globalization. By contrast, critics of globalization appear often to be more concerned with absolute inequality. Here again we will see that the difference in concepts of inequality carries weight for the position one takes in the globalization debate.

\section{Some stylized "facts"}

A common finding in the literature is that changes over time in the extent if income inequality at country level are uncorrelated with rates of economic growth. In other words, growth is "distribution neutral" on average. ${ }^{7}$ Figure 1 illustrates this lack of correlation found between changes in inequality and growth in average living standards. Each point in the figure represents two household surveys at different dates for the same country and the figure gives about 120 such "spells" spanning the 1990s. ${ }^{8}$ The change in inequality between the two surveys is plotted against the growth rate in mean household income (or consumption) per person between the same two surveys. Inequality is measured by the usual Gini index. The simple correlation coefficient between changes in the Gini index and the growth rates in Figure 1 is 0.06. Among growing economies, inequality rises about half the time, and falls half the time. This also holds for growing poor countries. Thus these data confirm other studies suggesting that the Kuznets Hypothesis - the proposition that with growth in a low-income country,

\footnotetext{
7 Evidence on this point can be found in, inter alia, World Bank (1990, 2000), Ravallion and Chen (1997), Ravallion (2001) and Dollar and Kraay (2002).

8 This is an updated version of the data set described in Ravallion and Chen (1997).
} 
inequality first increases then starts to fall after a certain point — has generally not been borne out by experience in growing developing countries (Bruno et al., 1998; Fields, 2001).

The observation that changes in inequality tend to be uncorrelated with growth rates has an important implication. Since growth tends to leave income shares unchanged on average, absolute poverty measures (whereby the poverty line has fixed real value) will tend to fall with growth. The same share of a larger pie means of course a higher income. The expected negative correlation between rates of poverty reduction and rates of growth across countries has been borne out by a large body of empirical research using household-level survey data for many countries. ${ }^{9}$ Granted there have been cases in which growth has left the poor behind in absolute terms, but they are the exception rather than the rule.

Is the world becoming more unequal in the current period of globalization? Measuring inequality amongst people in the world as a whole, different studies and different time periods give different answers to this question. Bourguignon and Morrison (2002) finds signs of slightly rising inequality from the 1970s to the early 1990s. Sala-i-Martin (2002) reports evidence suggesting a tendency for inequality to fall in the 1990s. Milanovic (2004) reports rising inequality in some sub-periods and falling inequality in others, with no clear trend.

However, even if one takes the view that inequality has been rising, it has clearly not increased enough to choke off the gains to the poor from growth in the world economy. Figure 2 gives estimates of the poverty rate for the developing world over the period 1981-2001. Over this 20 year period, the percentage of the population of the developing world living below $\$ 1$ per day was almost halved, falling from $40 \%$ to $21 \%$. The number of poor by this measure fell from 1.5 billion in 1981 to 1.1 billion in 2001.

\footnotetext{
9 Evidence on this point can be found in World Bank (1990, 2000), Ravallion (1995, 2001), Ravallion and Chen (1997), and Fields (2001).
} 
Some of these "stylized facts" about what has been happening to poverty and inequality in the world have been questioned. The claims often heard from critics of globalization that the world is becoming more unequal appear to stem in part from the fact that many poor countries are not participated in the growth of the world economy. Indeed, looking back over the last 100 years or so, initially poorer countries have tended to experience lower subsequent growth rates (Pritchett, 1997). Poor countries are not catching up with rich ones — indeed, it looks like the opposite has been happening. For example, an often quoted statistic is that the average income of the richest country in the world was about 10 times that of the poorest around the end of the nineteenth century but is closer to 60 times higher today. Furthermore, on top of this long run trend, there have been claims that inequality between countries has increased sharply since about 1980 (Milanovic, 2004). (We will return to the issue of how inequality between countries should be measured.)

Another issue that has sometimes been raised concerns the fact that the above discussion relates only to absolute poverty, whereby the poverty line has fixed real value. Measures of "relative poverty" in which the poverty line responds positively to the mean naturally show less impact of growth. Indeed, in the extreme case in which the poverty line is directly proportional to the mean, a growth process that raises all incomes by an equal proportion will leave measured poverty unchanged. One can question whether such a poverty measure makes any sense; while relative deprivation may matter to welfare, it surely cannot be argued that absolute levels of living are irrelevant. When one compares poverty lines across countries with their average consumption levels one finds higher poverty lines in richer countries, though the relationship tends to be quite inelastic amongst poor countries, consistent with the view that absolute deprivation dominates (Ravallion, 1994). However, as developing countries grow, the ides of 
what "poverty" means will undoubtedly evolve too. Then a sole focus on absolute poverty will overstate the importance of growth to poverty reduction in the longer-term.

The pro-globalization side of the debate has often pointed to the developing world's overall success against absolute poverty since the early 1980s as support for the view that globalization is good for poverty reduction. It is argued that pro-globalization policies in developing countries are pro-poor because they generate higher economic growth, which does not come with higher inequality and so reduces absolute poverty (see, for example, World Bank, 2002). However, a closer inspection of the aggregate poverty numbers, such as in Figure 2, immediately raises some doubts about the role played by globalization versus other factors. China is hugely important in the world's overall success against extreme poverty; indeed, the number of poor in the world (by the $\$ 1$ a day standard) outside China has remains quite stable over this period, at around 850 million (Chen and Ravallion, 2004b). As is clear from Figure 2, there was a dramatic decline in China's poverty incidence in the early 1980s; about 200 million people crossed the $\$ 1$ per day hurdle between 1981 and 1984. Note, however, that this largely preceded the country's external trade reforms (Chen and Ravallion, 2004c). More plausibly the sharp drop in poverty in China in the early 1980s was due to another kind of reform: the decollectivization of agriculture following Premier Deng's reforms starting in 1978.

Furthermore, while the evidence is compelling that growth tends to reduce absolute poverty, that does not imply that every policy that is good for growth will also reduce poverty. Specific growth-promoting policies in specific country contexts can have impacts on distribution that belie such generalizations. For example, Lundberg and Squire (2003) find evidence that trade openness tends to be inequality increasing. There is also some evidence of an interaction 
effect with mean income, such that trade openness tend to be associated with higher inequality in poor countries, but lower inequality in high-income countries (Barro, 2000; Ravallion, 2001).

The above issues have received attention in the literature, though all of them are sufficiently important and sufficiently contentious to merit further research. The rest of this paper will examine some issues that have received far less attention, related to what we mean by "inequality." It will be argued that differences between competing concepts of inequality influence the way empirical evidence is interpreted and hence the position one takes in the globalization debate.

\section{Divergence vs. between-country inequality}

Critics of globalization have pointed to data suggesting that inequality between countries has been rising since around 1980. The contribution of globalization per se to this trend is unclear. ${ }^{10}$ However, putting the attribution problem to one side, there is another important question about how inequality should be measured. The measures most widely quoted by the critics of globalization treat each country as one observation. The implicit value judgment here is that countries, not people, should get equal weight in assessing the fairness of the division of the gains from globalization. An alternative approach is to give people equal weight. Estimates of the decomposition of world inequality into between-country and within-country components have typically used population weights. ${ }^{11}$ By this alternative concept, all individuals at a given real income level get equal weight in assessing between-country inequality, no matter where they live. A person in China does not count less than a person in Chad at the same real income.

$10 \quad$ For further discussion see Williamson (1998) and O'Rourke (2002).

11 See, for example, Schultz (1998), Bourguignon and Morrison (2002) and Sala-i-Martin (2002)

For an overview of the theory of inequality decomposition see Cowell (2000). 
The choice between these concepts of inequality matters greatly to the message conveyed on how fairly the benefits of aggregate growth are being shared. If instead of weighting countries equally one uses population weights then the tendency for rising inequality between countries vanishes. ${ }^{12}$ Indeed, with population weighting, there is evidence of a trend decline in the between-country component of inequality since roughly the mid-1970s. In marked contrast to the series in which countries are weighted equally, the population-weighted series in Figure 3 suggests that inequality between countries is now the lowest it has been in half a century. The difference in the message conveyed by the two weighting schemes could hardly be less dramatic.

What arguments can be made for choosing between the two series in Figure 3? Some economists have seen this as a purely technical matter of what is "right" and "wrong." For example, Sala-i-Martin has argued that weighting countries equally is a "mistake that delivers a very misleading picture and one is led to conclude (wrongly) that there has been 'divergence big time"” (Sala-i-Martin, 2002, p.25-26; in the last phrase he quotes the title of Pritchett, 1997). However, intelligent people can disagree about whether countries or people should be weighted equally. Consider the inequality between two equal-sized groups, A and B, in which each person in group A has an income of $\$ 1$ per day while each person in B has an income of $\$ 10$. (So we abstract from inter-group inequality.) Now imagine instead that group B is only one tenth the size of A. Is your assessment of the extent of inequality between A and B any different with this change? No doubt some readers will say "no" on the grounds that either way a typical person in group A has only one tenth of the income as one in B. Others will say "yes," on the grounds that

12 There have been a number of recent estimates of the time series of global inequality, including Schultz (1998), Bourguignon and Morrison (2002), Sala-i-Martin (2002) and Milanovic (2004). The latter study is the most comprehensive in terms of the coverage of the underlying distributional data and so the following discussion will draw mainly on that study's results. 
with fewer people in group B, one's concern about the extent of inter-group inequality is diminished.

When assessing how rich countries are doing relative to poor countries it is natural to take the country as the unit of observation. Knowing that the income per capita of a rich country is 30 times greater (even at purchasing power parity) than a poor country has a salience for our comprehension of the extent of the disparities in the world. The practice of weighting countries equally is almost universally followed in the large macroeconomic literature on growth and distributional empirics. Weighting countries equally is a close cousin of the method used to measure "sigma convergence" in the literature on growth empirics. The rise in between-country inequality over the last 20 years that is evident in Figure 3 when countries are weighted equally is indicative of what is called (un-conditional) divergence in the growth literature. Weighting countries equally makes sense in a regression that is being used to test theories about the causes of cross-country differences in growth rates (say). In that case, each country can be thought of as a draw from the universe of all the combinations of country policies, shocks, initial conditions and outcomes.

It has been argued that countries are the relevant unit of observation for comparing policies, and for drawing conclusions about what policies work best for reducing inequality between countries. Milanovic (2004) makes this argument in favor of weighting countries equally. This view is more defensible for certain economy-wide policies than others, such as social sector policies, which are often developed and implemented at sub-national (even local) levels. However, for the sake of argument let us agree that policies are implemented at country level. Is this a compelling argument for weighting countries equally when assessing global inequality? It is the impacts of those policies on people that we care about. The lack of policy 
reform and growth in a small country surely cannot be deemed to cancel out the policy reforms that helped generate so much economic growth in China over the last 20 years or so. Yet that is what un-weighted inequality measures do. While it can be agreed that for purely descriptive purposes, and for testing the implications of certain growth models, one may not care about the population shares of countries when assessing inequality between them, weighting people unequally in such a seemingly arbitrary way can be questioned when - as is plainly the case in the globalization debate - one is attaching normative significance to measures of betweencountry inequality.

The practice of weighting countries equally when measuring inequality betweencountries also implies troubling inconsistencies in methodology. It is not clear why one would be happy to use population weights when measuring inequality within countries, but not between them. Indeed, one would probably never question the need to weight by household size (or the number of adult equivalents) when calculating an inequality measure from a sample survey for a given country, and the same logic surely applies to the between-country component of total inequality. Weighting countries equally rather than people is also inconsistent with the way one would normally calculate the global mean income. A measure of inequality is a summary statistic of the information on how income is found to vary with the quantile (such as percentile) of the population ranked by income. One would probably not even think of using the unweighted overall mean income, so why would one use un-weighted means at given percentiles of the distribution when measuring inequality?

Another defense of weighting countries equally starts by rejecting the implicit assumption in population weighting that individual welfare depends on "own income," and allowing instead the possibility instead that welfare also depends on country of residence. 
Population weights can be questioned in all circumstances in which group memberships have welfare significance independently of incomes. This can happen in a variety of ways. For example, the local political jurisdiction of residence can matter to one's access to local public goods. Group membership can also matter to one's ability to insure against income risk or smooth consumption. Social norms of behavior or "culture" are also formed in groups, and can influence welfare in important ways. ${ }^{13}$ There are ample precedents for attaching significance to geographic identity in public policy. The constitutions of a number of federations (including Australia and the U.S.) give states political representation in the upper houses of parliament, independently of their population sizes. Those living in smaller states thus get higher weight. Similarly, it is "one country-one-vote" at the United Nations and many other international organizations.

What is not so clear is how persuasive such arguments are for weighting countries equally rather than people in the present context. Yes, one can allow that country identity matters. However, it would seem hard to imagine that this type of argument would justify weighting countries equally. That surely goes too far in the other direction. Some sort of hybrid weighting scheme is called for, derived from an explicit assumption on the weight one attaches to country identity in assessing individual welfare. Suppose that the role of "country identity" can be captured by a country-specific multiplicative factor on the underlying function of own income that one uses to assess individual welfare in a given country. Then the appropriate weights will be products of population weights and these country-specific factors. It would seem extremely unlikely that the appropriate country factors would be the inverse population shares.

13 For a model of economic behavior incorporating group identities see Akerlof and Kranton (2000). Kanbur (2003) questions individualism in the context of a critique of the policy significance often attached to inequality decompositions. 
A further issue concerns the robustness of the population-weighted inequality series in Figure 3. China and India (the two most populous countries by far) naturally play an important role in the striking difference between the two series in Figure 3. The high rates of growth in China and (more recently) India since the mid-1980s have been a major inequality-reducing force between people in the world. Take these countries out of the population-weighted series and the decline in between-country inequality over the last two decades or so largely vanishes; the result is particularly sensitive to just one country, China. ${ }^{14}$ By the same token, assessments of how (population-weighted) inequality is changing between countries can be quite sensitive to errors in measuring growth in China and India. For example, there are reasons to suspect biases in the long-run estimates of China's rate of growth, stemming in part from deficiencies in the underlying administrative data sources, particularly at local level. (The practice of setting obligatory growth rate targets for local governments has not helped!) China's National Bureau of Statistics has gone a long way toward correcting these problems, but it still appears likely that the long-run rate of growth in national income per capita has been overestimated by 1-2 percentage points (Maddison, 1998; Wang and Meng, 2001). The rate of decline in inequality evident in Figure 3 when people are weighted equally is almost certainly overstated.

The sensitivity of the population-weighted series to including the most populous countries is not a good reason for weighting countries equally. However, that sensitivity does speak to the need for statistical caution in inferring that inequality is falling between countries from the population weighted series in Figure 3. How confident can one be in claiming that inequality is falling when that no longer holds if one drops just one country?

14 This has been noted by Schultz (1998), Sala-i-Martin (2002) and Milanovic (2004). 
As we have seen, the implicit values in empirical work matter greatly to the assessment one is drawn to make about the distributive justice of current globalization processes. And arguments can be made both ways.

\section{Vertical vs. horizontal inequalities}

The empirical question at stake in the globalization debate is often posed in terms of how mean gains from reforms vary by pre-reform income. Do the mean proportionate gains rise or fall as income increases? Studies deemed to be favorable to the supporters of globalization are those that find that the mean proportionate gains are just as high for the poor as the non-poor (see, for example, Dollar and Kraay, 2002).

This perspective emphasizes what can bet termed the "vertical" impacts of reform, i.e., the differences in mean impacts between people at different income levels. Critics of globalization, by contrast, appear often to be more concerned about what we can call the "horizontal" impacts, such as when anti-globalizers point to the fact that there are losers amongst the poor, even when the net gains to the poor as a whole are positive. Borrowing from the literature on inequality and taxation, we can define the horizontal impacts as the differences in impact amongst people who are ex ante equal in terms of welfare; such impacts indicate horizontal inequality in the reform. ${ }^{15}$

A conventional poverty or inequality measure implicitly attaches weight to both horizontal and vertical inequality. To see how, imagine that each person receives an income gain from the reform (which could be positive, negative or zero). We can calculate a pre-reform poverty and inequality measure (based on the distribution of incomes excluding these gains) and

15 For further elaboration of the various concepts of horizontal inequality found in the literature see Jenkins and Lambert (1999). 
a post-reform measure (including the gains). The difference between the two reveals the overall impact of the reform. One can then decompose the impact of a policy reform into "vertical" and "horizontal" components as follows. Define the conditional mean gain as the mean of these gains at a given level of income. Imagine replacing each person's actual gain by the conditional mean corresponding to that person's income and calculating the impact on the poverty or inequality measure with this new synthetic distribution. We can interpret this as the vertical component of the change in inequality or poverty. If there are no differences in the impacts by levels of income then the vertical component is zero. However, when some people amongst those at around the same initial income level incur a net loss from reform, while others enjoy a gain, this will add to inequality. To isolate this horizontal component we can also replace each person's actual gain by the deviation between that gain and the conditional mean, and again recalculate the summary statistic on this synthetic distribution. If the impact is predicted perfectly by pre-reform income then this horizontal component is zero. ${ }^{16}$ Ravallion and Lokshin (1994) derives such a decomposition for the impacts of trade reform on inequality and give and empirical example for a specific trade reform; I will return to this example below.

The issue is not then whether horizontal inequality is reflected in current aggregate measures but whether it is adequately reflected. Observers can reasonably object to the horizontal inequalities of globalizing reforms — quite independently of the impacts that those reforms have on conventional inequality or poverty measures. One possible reason is that the initial distribution of income (as measured in practice) need not be horizontally equitable. This can stem from the inadequacies of income as a welfare metric. There are conceptual and

16 The vertical and horizontal components need not add up exactly to the total change in measured poverty or inequality. A special case in which the decomposition is exact for proportionate gains (normalized by pre-reform income) is for the Mean Log Deviation measure of inequality; for details see Ravallion and Lokshin (2004). 
practical problem in measuring household "income" or "consumption," and in making cost-ofliving comparisons when prices and household characteristics vary (including the choice of the equivalence scales for dealing with differences in family size and demographics). ${ }^{17}$ Nor are standard measures (such as household income per person) likely to reflect well the extent of inequality within households or differences in access to non-market goods. These concerns point to the importance of introducing supplementary indicators of welfare into distributional assessments (Ravallion, 1996). If we think that certain types of households may in fact be poorer than measured incomes suggest then our attention will naturally be drawn to impacts on those household types, even if they have similar (measured) incomes. Peoples' subjective assessments of economic welfare and the fairness of the outcomes from economic transactions have been found to depend on a variety of factors, including how much effort different people supplied as well as their initial income. ${ }^{18}$ Reference-group effects on welfare - whereby the same income can yield different welfare for people in different reference groups, such as different neighborhoods — can also imply a concern for differences in impacts amongst people at the same ex ante income.

We can also care about horizontal inequalities even when we are happy with how economic welfare is measured. In the economics of public policy there is precedent for concern over horizontal inequality, notably in the context of income tax changes - though the point would appear to apply with equal force to other types of policy reform. For example, Pigou $(1949$, p.50) wrote that horizontal inequality created “...a sense of being unfairly treated...in itself an evil." Auerbach and Hassett (2002, p.1117) argue that one might want to put higher weight

$17 \quad$ A good overview of the issues and literature on welfare measurement can be found in Slesnick (1998). On the bearing that measurement choices can have on policy see Ravallion (1994). 18 For a survey of experimental evidence relevant to this point see Konow (2003). Subjective assessments of economic welfare have also revealed a more complex set if factors than typically postulated by economists (Ravallion and Lokshin, 2002). 
on horizontal inequities in a tax system on the grounds that "..large differences [in tax rates] amongst similar individuals, regardless of their source, might be viewed as intrinsically arbitrary, and therefore more costly to the social fabric."

Two recent studies of tax and transfer policies have shown how inequality or poverty measures can be re-defined to give higher weight to horizontal inequality. In the context of measuring the extent of horizontal inequality in a tax reform, Auerbach and Hassett show how an Atkinson (1970) index of social welfare can be decomposed into vertical and horizontal components in which the inequality aversion parameters can be different between the two. In a similar vein, Bibi and Duclos (2004) allow differential weights on the horizontal versus vertical components of the impacts of targeted transfers on the Foster-Greer-Thorbecke (1984) measure of poverty. The same ideas from the analysis of taxes and transfers carry weight in other areas of public policy including trade and other efficiency-oriented reforms.

In the context of reform we may deem it to be unfair that people at similar initial incomes are rewarded very differently. Such assessments will probably depend in part on whether people were aware of the risks they were exposed too, and could have taken actions to protect themselves. It is plain that many of the welfare losses from globalization stem from factors for which the losers are essentially blameless. When the sole employer in a company town is driven out of business we can hardly blame the town's workers and residents for the losses they incur.

In the case of trade reform, the household characteristics that are likely to matter most to the horizontal welfare impacts are those that influence net trading positions in relevant markets. Whether a household is a net demander or a net supplier of the specific goods and factors whose prices are changed by trade reform will depend on (amongst other things) its assets (for example, how much land an farm household controls will influence whether it is a net producer or net 
consumer of food), demographics (since this will naturally influence consumption patterns) and location (which will matter to both production and consumption opportunities). There is no obvious basis for thinking that these are characteristics that stem from choices for which one would fairly ask the households themselves to bear the adverse consequences of reform.

Such horizontal inequities can also interact powerfully with pre-existing social tensions — such as between different ethnic groups having different production and consumption behaviors - thus fuelling social conflict, and even violent conflict. Chua (2003, Chapter 4) describes how social conflict in parts of Africa has stemmed from the fact that different tribal groups have (for various, and contested, reasons) fared very differently under market-friendly regimes. To some extent these conflicts can be thought of as stemming from historical vertical inequalities between groups. However, it can be conjectured that a large share is horizontal, in that ex-ante similar people in different groups fare very differently under the market-oriented reform. There is no reason to suppose that a conventional inequality measure would weight the consequent social conflicts appropriately. Extreme horizontal inequalities raise concerns about social and political stability; the protests from the losers can be loud, even when the aggregate net gains are positive.

Conventional measurement practices may well underweight horizontal inequality. Indeed, the measure will remain exactly the same if we simply reorder all the incomes in a society; this property is variously called the "anonymity axiom" or the "symmetry axiom" in the theory of poverty and inequality measurement. Thus if a policy change results in one person loosing and another gaining, such that they swap places in the distribution, this will not have had any impact whatsoever on standard measures. Yet this kind of "churning" in the distribution is 
unlikely to go unnoticed by the people involved. One should not be surprised if the losers in the process are unhappy about the outcome, and that this fuels criticisms of the policies that led to it.

If we agree that these largely theoretical arguments suggest that the horizontal inequities of reform merit greater attention, the next question is whether horizontal inequalities are likely to be quantitatively important in the welfare outcomes of specific growth-promoting policy reforms, including trade reforms. We know from development experience that many of the things that promote growth can have both winners and losers among the poor, and for other income groups. This arises from the heterogeneity in economic circumstances, such as differences in net trading positions in relevant markets for goods and factors. For example, some of the poor are net suppliers of food while others are net demanders, which means that changes in the relative price of food associated with trade reform benefit some but hurt others, with these diverse impacts found both vertically and horizontally in the distribution of income. ${ }^{19}$ There can be heterogeneity in other dimensions of welfare at given incomes, such as associated with differences in access to publicly provided goods and services. Greater openness to external trade often increases the demand for skills that can be quite inequitably distributed in poor countries. Whether the poor gain relatively more than the non-poor from trade openness will depend crucially on antecedent inequalities in other dimensions, notably human capital.

Two examples illustrate the heterogeneity in impacts of trade reform. The first example relates to China's recent accession to the World Trade Organization (WTO). To provide a detailed picture of the welfare impacts of this trade reform, Chen and Ravallion (2004) use China's national rural and urban household surveys to measure and explain the welfare impacts of goods and factor price changes attributed to accession to the WTO. The price changes were

19 See, for example, the results of Ravallion and van de Walle (1991) on the welfare effects of higher rice prices in Indonesia. 
estimated using a general equilibrium model to capture both direct and indirect effects of the initial tariff changes. The welfare impacts were estimated as first-order approximations of a money metric of utility, based on a household model incorporating own-production activities, calibrated to the household-level data imposing minimum aggregation. In the aggregate, Chen and Ravallion find a positive impact of WTO accession on mean household income, but virtually no change in aggregate inequality and slightly lower aggregate poverty in the short term as a result of the reform. ${ }^{20}$ (The estimated impact on the Gini index for example was so small as to be almost undetectable.) However, there is still a sizable, and at least partly explicable, variance in impacts across household characteristics at given income. Rural families tend to lose; urban households tend to gain. There are larger impacts in some parts of the country than others. For example, one finds non-negligible welfare losses among agricultural households in the northeast — a region in which rural households are more dependent on feed grain production (for which falling relative prices are expected from WTO accession) than elsewhere in China. Vertical differences in pre-intervention incomes accounted for virtually none of the measured welfare impact of this trade reform.

The second example comes from research on the likely impacts of agricultural trade reform in Morocco. Here the simulated trade reform entailed the de-protection of cereal producers, through substantial reductions in tariffs on imported cereals. As in the China study, the price changes were estimated using a general equilibrium model and the welfare impacts were estimated as first-order approximations of a money metric of utility using a household survey; details can be found in Ravallion and Lokshin (2004). In this case, the results suggested that the trade reform would increase overall consumption inequality in Morocco. However, this was entirely due to the reform's impact on horizontal inequality; indeed, the vertical component

The results are documented fully in Chen and Ravallion (2004). 
- the contribution of the inequality in gains conditional on income — was inequality reducing. And, as in China, the horizontal welfare impacts are correlated with household demographics and location.

Simply averaging over such horizontal inequalities can miss a great deal of what matters to the debate on globalization, including social protection policies. Credible assessments of the likely welfare impacts (both horizontally and vertically) can clearly hold implications for social protection (though it is probably little more than wishful thinking to imagine that full compensation is feasible, given the informational and incentive constraints on targeted policies. ${ }^{21}$ ) It is important for policy discussions to recognize that diverse welfare impacts can lie under the surface of average impact calculations. ${ }^{22}$ In this light, claims made about the distributional impacts of trade or other reforms using cross-country regressions are of questionable relevance for policy in any specific country; such regressions can hide the heterogeneity in impacts within countries as well as between them. ${ }^{23}$

Horizontal inequality is a long-established inequality concept in the literature on inequality measurement, though its is a concept that has received less attention than vertical inequality in theoretical work. ${ }^{24}$ Measures of horizontal inequality have typically been applied to studying tax reforms, though the idea can be adapted to a wider range of reforms and economic changes. (In the present context, the relevant horizontal inequalities are not confined to horizontal impacts that can be measured in monetary units.) Like absolute inequality, horizontal

$21 \quad$ For a fuller discussion of this point see van de Walle (1998).

22 Kanbur (2001) provides a nice illustration of this point in the context of assessments of Ghana's performance in reducing absolute poverty.

23 For further discussion of the concerns about cross-country regressions in this context see Ravallion (2001).

24 For an overview of the theory and references see Jenkins and Lambert (1999). 
inequality has so far taken a back seat in studies by economists related to inequality and globalization.

None of this denies the importance of knowing the implications for aggregate poverty and inequality. That is surely the first-order issue in this context. Even when we care about horizontal inequity we would presumably want to balance that concern against other policy objectives, such as reducing absolute poverty. If one follows the critics of globalization who focus solely on the losers among the poor then one risks derailing the prospects for important poverty-reducing policy changes. At the same time, it must be recognized that to undervalue or even ignore the horizontal heterogeneity in impacts can give a seriously incomplete picture, and an unnecessarily narrow basis for policy.

\section{Relative inequality vs. absolute inequality}

So far we have been solely concerned with what is known as relative inequality in the literature on inequality measurement. Relative inequality depends on the ratios of individual incomes to the mean. If all incomes rise by the same proportion then relative inequality is unchanged. The stylized fact that growth or greater openness in developing countries tends not to be systematically associated with rising (or falling) inequality rests on this specific concept of inequality.

This contrasts with the concept of absolute inequality, which depends on the absolute differences in levels of living, rather than relative differences, following Kolm (1976). ${ }^{25} \mathrm{~A}$ measure of absolute inequality is unchanged if all incomes increase by the same amount. Consider an economy with just two households with incomes: $\$ 1,000$ and $\$ 10,000$. If both

25 There are also intermediate measures, which contain the concepts of absolute and relative inequality as extreme cases; see, for example, Bossert and Pfingsten (1990). 
incomes double in size then relative inequality will remain the same; the richer household is still 10 times richer. But the absolute difference in their incomes has doubled, from $\$ 9,000$ to $\$ 18,000$. Relative inequality is unchanged but absolute inequality has risen sharply.

While relative inequality has been the preferred concept in empirical work in development economics, perceptions that "inequality is rising" may well relate more to absolute inequality. That is one interpretation of what people mean when they talk about the "gap between the rich and the poor," and the "widening economic divide" (International Forum on Globalization, 2002). Observers such as citizens and NGO's working in developing countries can easily see the rising absolute gap in living standards between selected poor people (possibly those an NGO works with) and selected "rich" people. The fact that the proportionate gap may well be unchanged is less evident to the naked eye, if only because this requires knowledge of the overall mean. Furthermore, there is little obvious reason for assuming that it is the relative inequalities in incomes (rather than absolute inequalities) that matter instrumentally to valued social outcomes. Arguably inequalities in power relate more to absolute inequality of income than relative inequality. Many people think about "inequality" in absolute terms. Careful surveys of university students asked them which of two income distributions was more unequal; $40 \%$ of the students were found to base their answers on a concept of absolute inequality, while for 60\% it was relative inequality (Amiel and Cowell, 1999).

Here again, the value judgments made about what "inequality" means have considerable bearing on the position one takes in the globalization debate. Finding that the share of income going to the poor does not change on average with growth does not mean that "growth raises the incomes (of the poor) by about as much as it raises the incomes of everybody else" (The Economist, May 27, 2000, p.94). Given existing inequality, the income gains to the rich from 
distribution-neutral growth will of course be greater than the gains to the poor. In the above example of two households, the income gain from growth is 10 times greater for the high-income household. To say that this means that the poor "share fully" in the gains from growth is clearly a stretch. And the example is not far fetched. For the richest decile in India, the income gain from distribution-neutral growth will be about four times higher than the gain to the poorest quintile; it will be 15-20 times higher in Brazil or South Africa.

The common empirical finding in the literature that changes in relative inequality have virtually zero correlation with rates of economic growth naturally carries little weight for those who are concerned instead about absolute inequality. In Figure 4 the relative inequality index in Figure 1 has been replaced by the absolute Gini index, based on absolute differences in incomes (not normalized by the mean). In marked contrast to Figure 1, a strong positive correlation emerges (a correlation coefficient of 0.64). The absolute gap between the rich and the poor tends to rise in growing economies, and fall in contracting ones.

If you are a relativist then you might conclude from Figure 1 that there is no aggregate trade-off between economic growth and reducing inequality, though one should note that this is only true on average; there may well be a trade off in specific country circumstances. If one is an absolutist, then an aggregate trade-off is implied by Figure 4: in a typical developing country, someone who values lower absolute inequality must be willing to have less growth and (as we will see below) higher absolute poverty.

The distinction between absolute and relative inequality also has bearing on assessments of the prospects for reducing poverty through economic growth. Naturally, what happens to inequality during the growth process is relevant to its impact on poverty. A widely used benchmark for quantifying the impact of future growth on poverty is to assume that relative 
inequality does not change. For example, Chen and Ravallion (2004) show that for the developing world as a whole in 2001, the poverty gap index (for the "\$1 per day" poverty line at 1993 Purchasing Power Parity) has an elasticity with respect to the mean holding relative inequality constant of -2.3 . If all income levels grow at the same rate then the aggregate poverty gap index will fall at a rate of $4.6 \%$ per annum for a growth rate of $2 \%$ per annum in mean household income per capita. What would happen if instead constant absolute inequality was taken as the distributional benchmark? Repeating the Chen-Ravallion calculations but this time holding absolute inequality constant, I find that the elasticity rises sharply to $-11.4 .^{26}$ So instead of the poverty gap falling at a rate of $4.6 \%$ per annum for a growth rate of $2 \%$ per annum, the same growth rate keeping absolute inequality constant would see the poverty gap falling at a remarkable $23 \%$ per annum.

Of course, all such calculations are fanciful at best unless it can be established how one could achieve such a growth process in reality. That is a moot point. However, these simple calculations do at least serve to illustrate how sensitive our assessments of the impact on poverty of distribution-neutral growth can be to the concept of inequality we use in defining what "distribution-neutral" means.

Economists specializing on income distribution are well aware of the distinction between absolute and relative inequality, though it is hardly ever mentioned in empirical work on growth and distribution. ${ }^{27}$ Contributions to the globalization debate, in both popular and academic forums, have rarely been explicit about which concept is being used. Indeed, critics of

26 It is readily verified that elasticity of the poverty gap $(P G)$ index with respect to the mean holding absolute inequality constant (call this $\eta^{A}$ ) is given by $\eta^{A}=\left(\eta^{R}-1\right) \mu / z$ where $\eta^{R}=1-H / P G$ is the corresponding elasticity holding relative inequality constant, where $H$ is the headcount index of poverty.

27 An exception is Pritchett (1997). Fields (2001) notes that absolute inequality exists as a concept, though he quickly moves on to focus solely on relative inequality. 
globalization are often vague about what they mean by "inequality," though what they have in mind appears to be closer to absolute inequality than relative inequality. Defenders of globalization invariably point to evidence on relative inequality without mentioning that it is not the only possible concept of inequality and that the results obtained, and their interpretation for country policy, depend crucially on the choice.

Yet the evaluative judgments drawn about the distributional changes associated with globalization may depend crucially on whether one thinks about inequality in absolute terms or relative terms. There is no economic theory that tells us that inequality is relative, not absolute. It is not that one concept is right and one wrong. Nor are they two ways of measuring the same thing. Rather, they are two different concepts. The revealed preferences for one concept over another reflect implicit value judgment about what constitutes a fair division of the gains from growth. ${ }^{28}$ Those judgments need to be brought into the open and given critical scrutiny before one can take a well-considered position in this debate.

\section{Conclusions}

Both sides of the globalization debate often use the term "inequality" as though we all agree on exactly what that means. But we almost certainly don't all agree. And that could well be the nub of the matter. This paper has demonstrated that the factual claims one hears about what is happening to inequality in the world depend critically on value judgments embedded in standard measurement practices. The paper has highlighted three such issues: whether one weights people equally or countries equally when assessing what is happening to global

28 In the theory of inequality measurement the issue is closely related to whether or not one accepts an axiom variously referred to as "income homogeneity" or "scale independence." 
inequality, what weight one attaches to horizontal inequalities and whether one focuses on relative inequality or absolute inequality in assessing the welfare impacts of globalization.

Forming defensible value judgments on each of these issues is hardly straightforward, and the paper has illustrated that arguments can be made both ways. Readers should form their own judgments as to what side they take on each of these issues. But this discussion points to some tentative conclusions. On the first issue, while it is simplistic to say that it is a purely technical "mistake" to not weight by population sizes, it can be agreed that there is something troubling about comparing inequality among countries ignoring the (huge) differences in their populations - thus giving higher weight to people living in smaller countries. Whether population weights are the right approach is still unclear, given that country identity can matter to welfare. Neither weighing method is ideal, but weighting countries equally would seem hard to defend when making normative judgments about inequality.

On the second issue, while knowing what is happening to aggregate inequality and poverty is clearly of first-order importance, horizontal inequalities need to get more attention than they typically do in assessments of the welfare impacts of policy reforms. Conventional inequality measures may well undervalue horizontal inequality. In this respect, the globalization debate looks like a debate between two ships passing in the dark of night. One side says that inequality has been unchanged in the aggregate and (hence) that poverty has fallen; the other side points to the losers amongst the poor. Arguably both are right.

On the third issue, both sides of the globalization debate need to be clearer about whether one is talking about absolute or relative inequality and to recognize that the other side may not share their concept. Relative inequality has been the more prominent concept in applied work by economists, though arguably it is absolute inequality that most people see in the daily lives, and 
that motivates their concerns about distributive justice. Greater attention to absolute inequality would help inform important debates about development, including globalization. However, the trade-offs with other valued goals, including fighting absolute poverty, need to be confronted explicitly.

Contributions to the globalization debate — including both academic and popular contributions - have rarely acknowledged the differences in values that underlie the seemingly conflicting evidence on what has been happening to inequality and poverty. Most readers of the popular press and the web sites reporting on this topic do not see the embedded value judgments in the "facts" presented to them. It seems unlikely that most protagonists in this debate are deliberately duping the public; indeed, there appears to be some common ground of values, such as in the shared concern about absolute poverty. Hopefully then the debate can move on to address more directly the competing concepts of inequality that lie at the heart of the matter. 
Figure 1: Relative inequality and growth in mean household income per capita

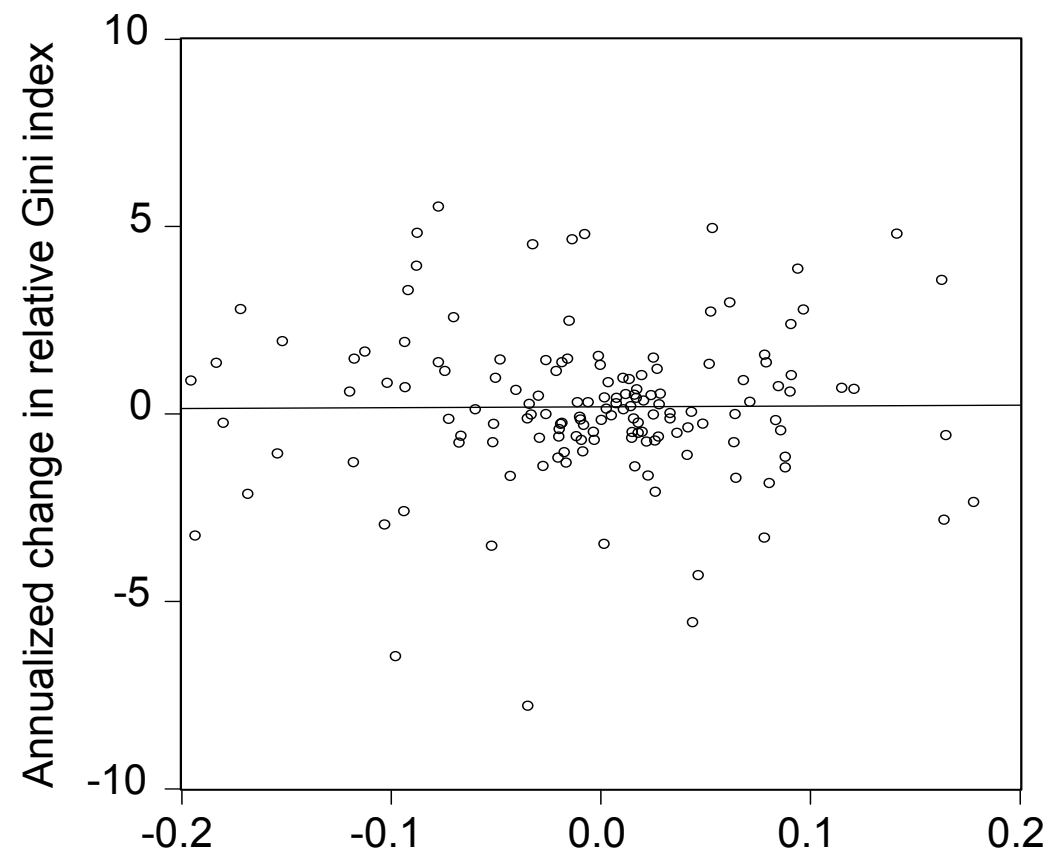

Annualized change in log mean

Source: Author's calculations from the World Bank's Global Poverty Monitoring data base at http://www.worldbank.org/research/povmonitor/ 
Figure 2: Poverty incidence in the developing world 1981-2001

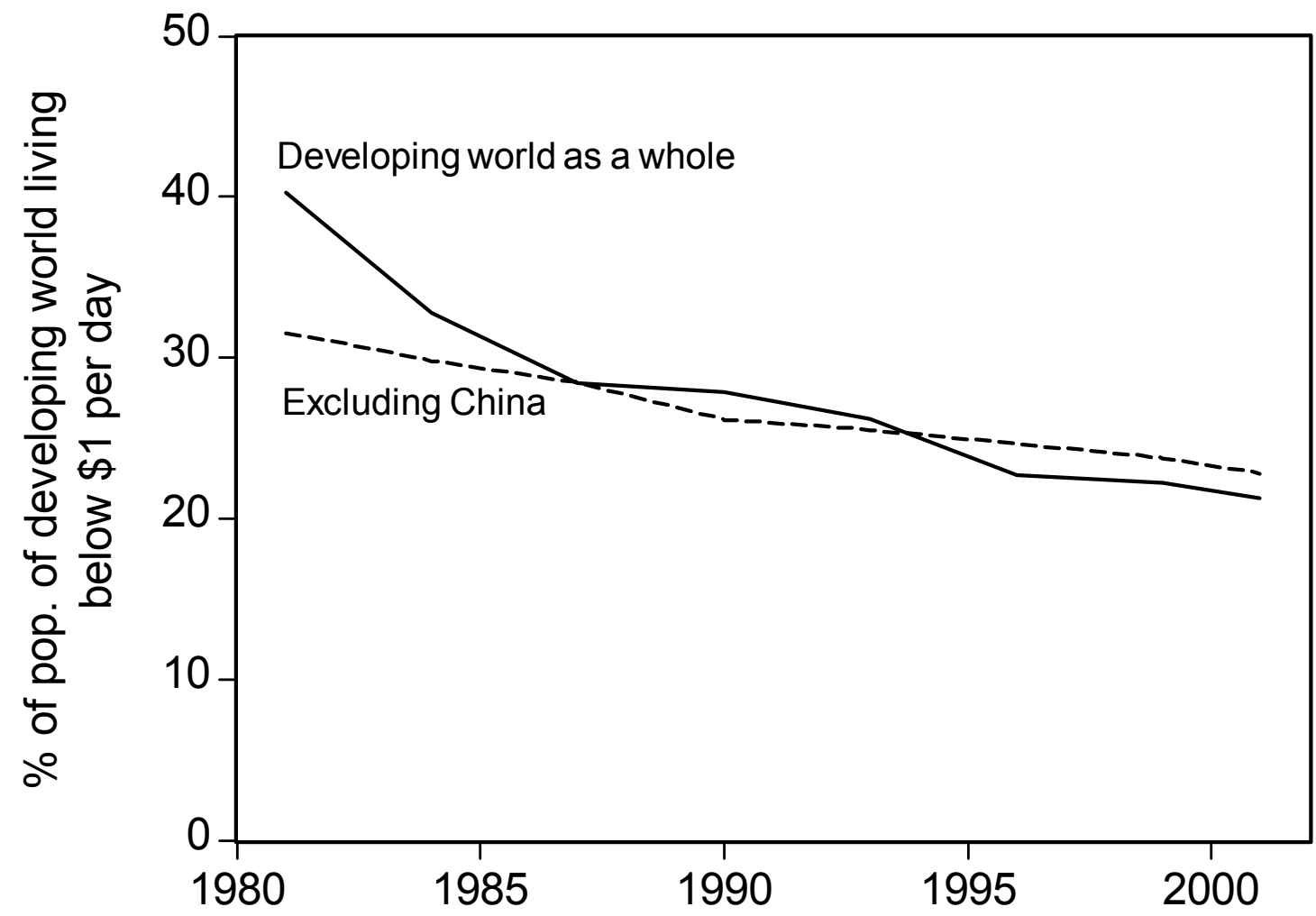

Note: The figure gives the percentage of the population of low and middle-income countries estimated to living households with consumption or income per person less than $\$ 32.74$ per month at 1993 Purchasing Power Parity. Source: Data from Chen and Ravallion (2004b). 
Figure 3: Gini indices of GDP per capita across countries under alternative weighting schemes

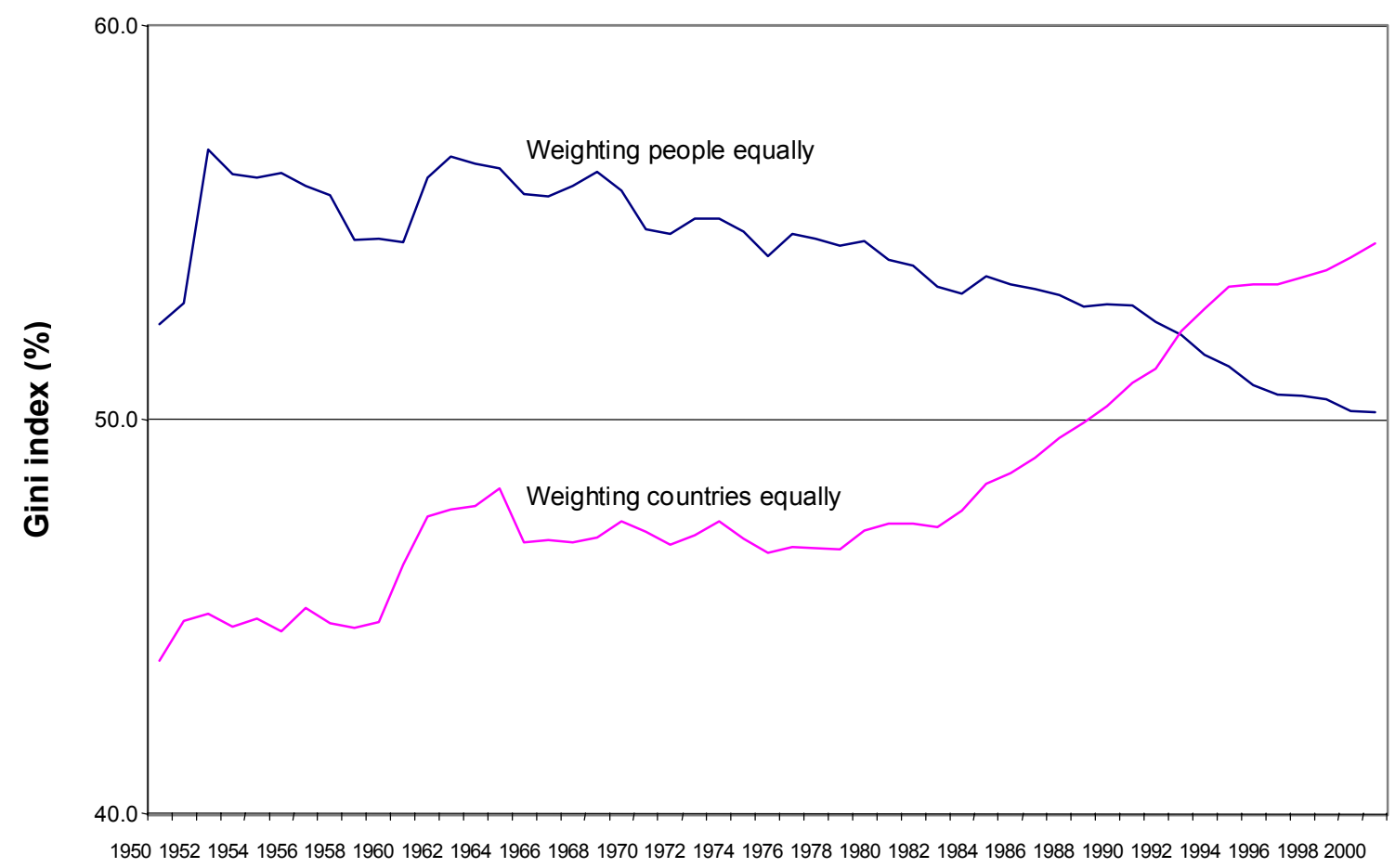

Source: Milanovic (2004) 
Figure 4: Absolute inequality and growth in mean household income per capita

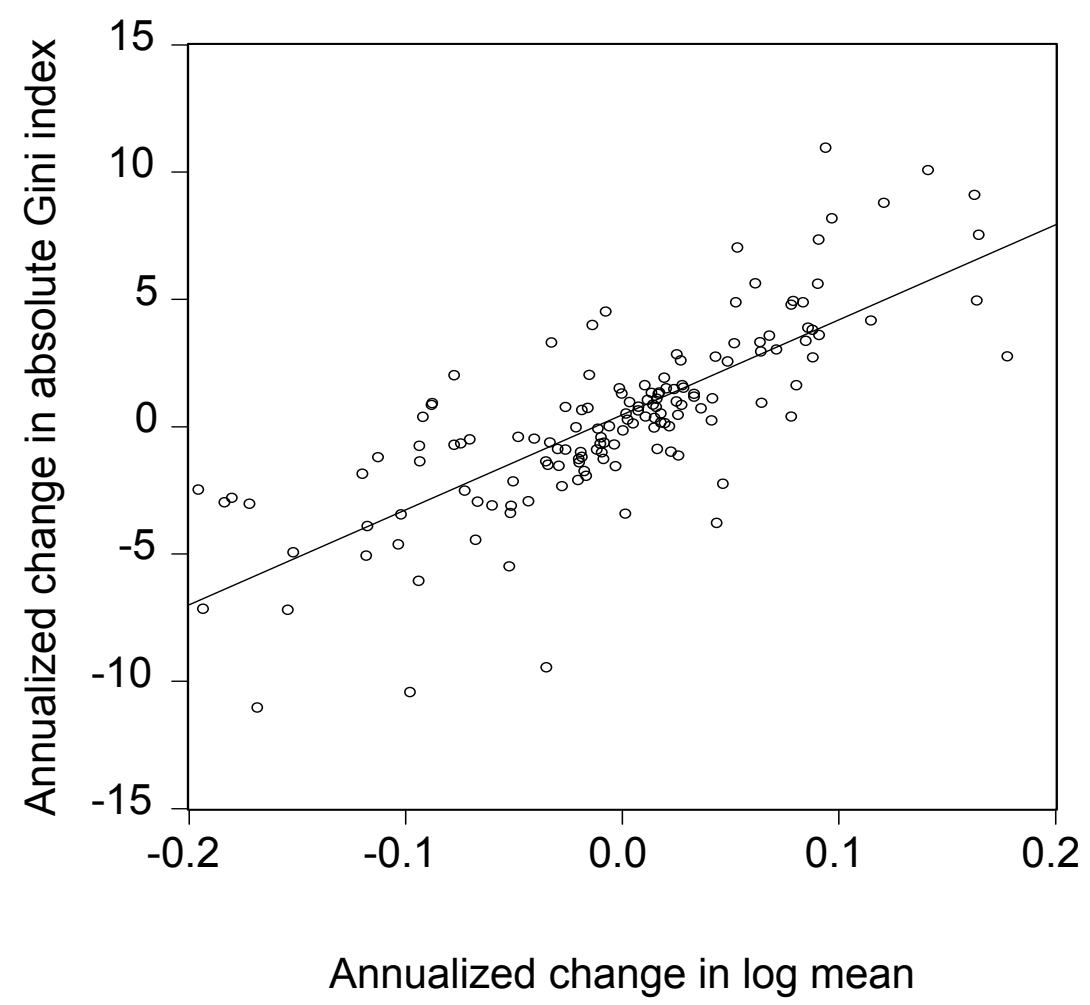

Source: Author's calculations from the World Bank's Global Poverty Monitoring data base at http://www.worldbank.org/research/povmonitor/ 


\section{References}

Akerlof, George, and Rachel Kranton. 2000. "Economics and Identity." Quarterly Journal of Economics 115(3): 715-53.

Amiel, Yoram, and Frank Cowell. 1999. Thinking about Inequality: Personal Judgment and Income Distributions. Cambridge, Mass.: Cambridge University Press.

Atkinson, Anthony B. 1970. "On the Measurement of Inequality." Journal of Economic Theory 2: $244-263$.

Auerbach, Alan J., and Kevin A. Hassett. 2002. "A New Measure of Horizontal Equity.” American Economic Review 92(4): 1116-1125.

Barro, Robert. 2000. "Inequality and Growth in a Panel of Countries." Journal of Economic Growth 5: 5-32.

Basu, Kaushik. 2003. "Globalization and the Politics of International Finance: The Stiglitz Verdict." Journal of Economic Literature 41: 885-899.

Bibi, Sami and Jean-Yves Duclos. 2004. "Equity and Policy Effectiveness with Imperfect Targeting.” Mimeo, Université Laval, Québec.

Bossert, W. and A. Pfingsten. 1990. "Intermediate Inequality: Concepts, Indices and Welfare Implications." Mathematical Social Sciences 9: 117-134.

Bourguignon, Francois, and Christian Morrison. 2002. "Inequality Among World Citizens: 1820-1992.” American Economic Review 92(4): 727-744.

Bruno, Michael, Martin Ravallion, and Lyn Squire. 1998. "Equity and Growth in Developing Countries: Old and New Perspectives on the Policy Issues." In V. Tanzi and K. Chu, eds., Income Distribution and High-Quality Growth. Cambridge, Mass.: MIT Press.

Chen, Shaohua, and Martin Ravallion. 2004a. "Household Welfare Impacts of WTO Accession 
in China." World Bank Economic Review. in press.

Chen, Shaohua, and Martin Ravallion. 2004b. "How Have the World's Poorest Fared Since the Early 1980s?" [http://www.worldbank.org/research/povmonitor/]. . 2004c. “China's (Uneven) Progress Against Poverty.” Mimeo. Development Research Group, World Bank, Washington, D.C.

Chua, Amy. 2003. World on Fire. New York: Anchor Books.

Cowell, Frank. 2000. "Measurement of Inequality." In A.B. Atkinson and F. Bourguignon, eds., Handbook of Income Distribution. Amsterdam: North-Holland.

Dasgupta, Partha. 2003. “What Do Economists Analyze: Values or Facts?” Paper presented at the conference, The Place of Value in a World of Facts, London School of Economics.

Dollar, David, and Aart Kraay. 2002. "Growth is Good for the Poor." Journal of Economic Growth. 7(3): 195-225.

Fields, Gary S. 2001. Distribution and Development. New York: Russell Sage.

Foster, James., J. Greer, and E. Thorbecke. 1984. “A Class of Decomposable Poverty Measures”, Econometrica 52: 761-765.

International Forum on Globalization. 2002. Alternatives to Economic Globalization: A Better World is Possible. San Francisco: Berrett-Koehler.

Jenkins, Stephen P., and Peter J. Lambert. 1999. "Horizontal Inequality Measurement:

A Basic Reassessment.” In J. Silber, ed., Handbook of Income Inequality Measurement. Boston, Mass.: Kluwer Academic Publishers.

Kanbur, Ravi. 2001. "Economic Policy, Distribution and Poverty: The Nature of Disagreements," World Development. 29(6): 1083-1094. . 2003. "The Policy Significance of Inequality Decompositions.” Mimeo. Cornell 
University.

Kolm, Serge. 1976. “Unequal Inequalities I.” Journal of Economic Theory 12: 416-442.

Konow, James. 2003. "Which is the Fairest One of All? A Positive Analysis of Justice Theories." Journal of Economic Literature 41: 1188-1239.

Lundberg, Mattias, and Lyn Squire. 2003. "The Simultaneous Evolution of Growth and Inequality." The Economic Journal 113: 326-344.

Maddison, Angus. 1998. Chinese Economic Performance in the Long Run. Paris: OECD.

Milanovic, Branko. 2004. Worlds Apart: Global and International Inequality 1950-2000. Princeton University Press. forthcoming.

O’Rourke, Kevin. 2002. “Globalization and Inequality: Historical Trends,” Aussenwirtschaft 57(1): 65-101.

Pigou, A.C. 1949. A Study in Public Finance, Third Edition. London: Macmillan.

Pritchett, Lant. 1997. “Divergence, Big Time.” Journal of Economic Perspectives 11(3): 3-17.

Putnam, Hilary. 2002. The Collapse of the Fact/Value Dichotomy. Cambridge, Mass.: Harvard University Press.

Ravallion, Martin. 1994. Poverty Comparisons. Harwood Academic Books. Chur, Switzerland. . 1995. "Growth and Poverty: Evidence for Developing Countries in the 1980s."

Economics Letters 48: 411-417.

. 1996. "Issues in Measuring and Modeling Poverty.” Economic Journal

106 (September): 1328-1344.

. 2001. "Growth, Inequality and Poverty: Looking Beyond Averages."

World Development 29(11): 1803-1815.

. 2003. "The Debate on Globalization, Poverty and Inequality: Why Measurement 
Matters.” International Affairs 79(4): 739-754.

. 2004. "Pro-Poor Growth: A Primer." Policy Research Working Paper 3242.

World Bank, Washington, D.C..

Ravallion, Martin, and Shaohua Chen. 1997. "What Can New Survey Data Tell Us about Recent Changes in Distribution and Poverty?" World Bank Economic Review 11(2): $357-82$.

Ravallion, Martin, and Michael Lokshin. 2002. "Self-Rated Economic Welfare in Russia." European Economic Review 46(8): 1453-1473.

. 2004. "Gainers and Losers from Agricultural Trade Reform in Morocco."

Policy Research Working Paper, World Bank, Washington, D.C. forthcoming.

Ravallion, Martin, and Dominique Van de Walle. 1991. "The Impact on Poverty of Food Pricing Reforms: A Welfare Analysis for Indonesia.” Journal of Policy Modeling 13: 281-299.

Sala-i-Martin, Xavier. 2002. "The Disturbing 'Rise' of Global Income Inequality.” NBER Working Paper 8904.

Schultz, T. Paul. 1998. "Inequality in the Distribution of Personal Income in the World: Changing and Why." Journal of Population Economics 11(3): 307-344.

Slesnick, Daniel T. 1998. "Empirical Approaches to the Measurement of Welfare." Journal of Economic Literature 36(4): 2108-2165.

Van de Walle, Dominique. 1998. “Targeting Revisited.” The World Bank Research Observer 13(2): 231-48.

Wang, Xiaolu, and Lian Meng. 2001. "A Re-evaluation of China's Economic Growth.” China Economic Review 12(4): 338-346. 
Williamson, Jeffrey G. 1998. "Globalization and the Labor Market: Using History to Inform Policy.” In P. Aghion and J. Williamson, eds., Growth, Inequality and Globalization. Cambridge, Mass.: Cambridge University Press.

World Bank. 1990. World Development Report: Poverty. New York: Oxford University Press. 2000. World Development Report: Attacking Poverty. New York: Oxford University Press. . 2002. Globalization, Growth and Poverty. Washington DC. 